\title{
Prevalence, antimicrobial susceptibility patterns, serotypes and risk factors for group B streptococcus rectovaginal isolates among pregnant women at Kenyatta National Hospital, Kenya; A cross-sectional study
}

Jisuvei Clayton Salano ( $\nabla$ salano.clayton@gmail.com )

kenyatta national hospital https://orcid.org/0000-0002-2210-4631

Osoti Alfred

University of Nairobi

Maina Anne Njeri

University of Nairobi

Research article

Keywords: Group B streptococcus, Pregnant women, Antimicrobial susceptibility, Serotypes, Kenya

Posted Date: December 15th, 2019

DOl: https://doi.org/10.21203/rs.2.18967/v1

License: @ (i) This work is licensed under a Creative Commons Attribution 4.0 International License. Read Full License 


\section{Abstract}

Background: Estimates of group B streptococcus (GBS) disease burden, antimicrobial susceptibility, and serotypes in pregnant women are limited for many resource-limited countries including Kenya. These data are required to inform recommendations for prophylaxis and treatment of infections due to GBS.

Methods: We evaluated the prevalence, antimicrobial susceptibility patterns, serotypes, and risk factors associated with rectovaginal GBS colonization among pregnant women receiving antenatal care at Kenyatta National Hospital (KNH) between August and November 2017. Consenting pregnant women between 12 and 40 weeks of gestation were enrolled. Interview-administered questionnaires were used to assess risk factors associated with GBS colonization. An anorectal swab and a lower vaginal swab were collected and cultured on Granada agar for GBS isolation. Positive colonies were tested for antimicrobial susceptibility to penicillin G, ampicillin, vancomycin, and clindamycin using the disk diffusion method. Serotyping was performed by latex agglutination. Logistic regression was used to identify factors associated with GBS colonization.

Results: A total of 292 women were enrolled. Median age was 30 years (Interquatile range $\{$ IQR\} 26-35) with a median gestational age of 35 weeks (IQR 30-37). Overall GBS was identified in 60/292 (20.5\%) of participants. Among the positive isolates, resistance was detected for penicillin G in 42/60 (72.4\%) isolates, ampicillin in 32/60 (55.2\%) isolates, clindamycin in 14/60 (30.4\%) isolates, and vancomycin in $14(24.1 \%)$ isolates. All ten GBS serotypes were isolated, and $37 / 53(69.8 \%)$ of GBS positive participants were colonized by more than one serotype. None of the risk factors was associated with GBS colonization.

Conclusion: The prevalence of GBS colonization was high among mothers attending antenatal clinic at $\mathrm{KNH}$. In addition, a high proportion of GBS isolates were resistant to commonly prescribed intrapartum antibiotics. Hence, other measures like GBS vaccination is a potentially useful approaches to GBS prevention and control in this population. Screening of pregnant mothers for GBS colonization should be introduced and antimicrobial susceptibility test performed on GBS positive samples to guide antibiotic prophylaxis.

\section{Introduction}

Streptococcus agalactiae also called group B streptococcus (GBS), causes invasive infections mainly in pregnant women and neonates (1). Temporary GBS colonization of the female urogenital tract is a known causative factor of neonatal infections acquired during the childbirth process (2). Acquisition of GBS can be perinatal during labour or inutero through transmission of the bacteria from the maternal vaginal or anorectally colonized mucosa. GBS is also a risk factor for neonatal sepsis and mortality that is associated with preterm birth (3). Neonatal GBS infection can be early or late onset with early-onset disease (EOD) ensuing within the first 7 days of life and presents as pneumonia, meningitis, and sepsis that carries a mortality rate of up to $20 \%(2)$.

Global rates of GBS colonization vary widely (4) with high prevalence rates of between $15 \%$ and $33 \%$ being reported in the United States, Jordan and Gambia (5) while low prevalence rates of less than $10 \%$ have been reported in Italy, Turkey and Iran (6). Though excellent data on GBS exists among developed countries, there is paucity of information on the rectovaginal colonization and associated maternal and neonatal complications due to GBS as well as serotypes in circulation, among many resource limited countries $(5,7)$. Among the few GBS studies conducted in sub-Sahara Africa, high colonization rates of $23 \%$ and $16.5 \%$ have been reported in Tanzania and Malawi respectively (7). In the most recent study in Kenya, Seale and Koech (8) reported a GBS prevalence of $12 \%$ among expectant mothers in Kilifi county while an earlier study by Salat et al done in 2009 , found a high prevalence of $25.2 \%$ among pregnant women at $\mathrm{KNH}$ (9). Even so, 
these two studies were limited in their scope to the prevalence and risk factors of GBS colonization but failed to investigate the antimicrobial susceptibility or serotypes of isolated GBS in their populations.

Neonatal sepsis contributes to $7 \%$ of neonatal mortality deaths in Kenya (10) with Escherichia coli as the main associated causative agents (11). The contribution of GBS on causation of neonatal sepsis in Kenya has received little focus; this is despite the overwhelming evidence from developed countries that has associated rectovaginal GBS colonization with EOD (12). Unpublished hospital statistics from KNH for the period January 2015 to December 2015 ranked neonatal sepsis as the highest infectious cause of neonatal death at $20 \%$. Based on the year $2015 \mathrm{KNH}$ statistics and an estimated $25.2 \%$ GBS prevalence, approximately 500 neonates die annualy translating to two deaths daily from early onset GBS disease (13). The GBS related infant mortality may even be higher in lower resource facilities in the country.

In Kenya, pregnant women are not routinely screened for rectovaginal GBS colonization. As such, there is paucity of data on the prevalence, antimicrobial susceptibility pattern, serotypes and risk factors of rectovaginal GBS colonization in Kenya. This study sought to contribute to this knowledge gab by determining the prevalence, serotypes, antimicrobial susceptibility paters and risk factors to GBS rectovaginal colonization among pregnant women in this population.

\section{Methods}

This was a cross sectional study conducted between August and November 2017. A population of pregnant women between the gestational ages of 12 to 40 weeks receiving antenatal care (ANC) at KNH was used. The study was conducted at KNH ANC clinic. KNH is the largest national reference hospital in Kenya. The ANC clinic attends to an average of 120 women each clinic day (13).

Inclusion criteria

Pregnant women without pregnancy complications such as placenta previa and vaginal bleeding and those above 18 years were included in the study. Women with current history of per vaginal bleeding, raptured membranes, in labour and those having been on antibiotics treatment within two weeks prior to the study were excluded.

Data Collection Instruments

Interviewer-administered questionnaires were used to gather obstetric and other study relevant information. Laboratory samples collected were two swabs, one from the lower vagina and the other from the anorectal area. Sterile Dacron swabs were used in collecting the samples.

In summary: the participant lay on the examination couch in a semi-lithotomy position and without speculum placement, the vagina labia were parted and the lower vagina swabbed using a sterile Dacron swab, immediately after, the swab was inoculated on an appropriately labelled group B streptococcus selective agar (GBSA/granada) plate (Hardy diagnostic). With the second swab, the anorectal area was swabbed and immediately inoculated on an appropriately labelled GBSA plate. The plate was placed in a cooler box and transported to the laboratory within 6 hours of sample collection.

\section{GBS isolation}

In the lab, plates were streaked and incubated anaerobically at $35 \pm 2{ }^{0} \mathrm{C}$ for $18-24$ hours as per the GBSA medium manufactures' instruction. After 24 hours, the plates were inspected for growth. GBS positive cultures were identified by the characteristic orange coloured colonies on GBSA agar. Gram stain was used to confirm the orange colonies as streptococcus.

A portion of GBS positive colonies was picked and stored at $-20^{\circ} \mathrm{C}$ in skimmed milk until testing for GBS serotypes. 
Another portion of GBS positive colonies was picked and emulsified in a clean test tube containing sterile normal saline for antimicrobial susceptibility testing.

Antimicrobial susceptibility testing

Antimicrobial susceptibility profile of isolated GBS was tested using disk diffusion test. The turbidity of the emulsified colonies was standardised to 0.5 McFarland and inoculated on Muller Hinton Agar enriched with $5 \%$ sheep blood.

Penicillin G-10 $\mu$ g (Hardy diagnostic, Lot: 385950), ampicillin-10 $\mu$ g (Hardy diagnostic, Lot: 391375), clindamycin-2 $\mu \mathrm{g}$ (Hardy diagnostic, Lot: 384766) and vancomycin-30 $\mu \mathrm{g}$ (Hardy diagnostic, Lot: 388310) drug discs were placed on the surface of the plate equidistant from each other and the plates incubated anaerobically at $35 \pm 2{ }^{0} \mathrm{C}$ for $18-24$ hours. The zones of inhibition as set by Clinical and Laboratory Standards Institute (CLSI) 2011 (penicillin G-10units, ampicillin$10 \mu \mathrm{g}$, clindamycin-2 $\mu \mathrm{g}$ and vancomycin30 $\mu \mathrm{g}$ ) were used to determine the susceptibility of GBS to the tested drugs. CLSI 2011 guidelines (14) were used in performing this test. The antibiotics used in the susceptibility tests are those used for intrapartum management of GBS at KNH (13).

Serotyping

Serotyping was determined by latex agglutination test using Immulex Strep-B kit (Statens serum Institute-Denmark Article 54991/Lot: V3). For each GBS isolate, on a carbon test card with 10 circles labelled corresponding to the each GBS serotypes, a $10 \mu \mathrm{l}$ drop containing GBS colonies emulsified in normal saline was placed. A $10 \mu \mathrm{l}$ drop of the corresponding Immulex Strep B antisera was added to the suspension and mixed before gently rocking while observing for agglutination. This test was done according to the manufacturer's instruction.

\section{Data Analysis}

Collected data was analysed using STATA ${ }^{\circledR}$ version 13. Participant characteristics were analysed descriptively, Mann Whitney $U$ test was used to compare characteristics between colonised and uncolonized women while logistic regression was used to identify factors associated with GBS colonization. P values $\leq 0.05$ were taken to be statistically significant.

\section{Results}

Between August and November 2017, a total of 350 pregnant women were screened, 292 eligible pregnant women between 12 and 40 weeks gestation consented and were enrolled to participate in the study. From these, 292 questionnaires were fully filled and 292 (100\%) vaginal swab samples and 288 (98.6\%) anorectal swab samples collected for GBS culture. Four participants declined to have anorectal swabs collected.

Socio-demographic characteristics

The median age of participants was 30 years (IQR 26-35). About one in five $(n=55,18.8 \%)$ were aged below 25 years, majority ( $n=177,60.6 \%)$ were aged between 26 to 35 years while another one in five were aged 36 years or older $(n=60$, $20.5 \%)$. The median gestation age of study participants was 35 weeks (IQR $30-37)$. Less than half $(n=132,45.2 \%)$ of the participants were of gestation age 34 weeks and below while $15.1 \%(n=44)$ were term i.e. greater than 37 weeks

Obstetric and clinical characteristics

Half of the participants $(n=156,53.4 \%)$ were multiparous with a median parity of three pregnancies (IQR 2-4). Only 53 $(18.2 \%)$ of the pregnant women were primigravida. Approximately three quarters of participants $(n=210,71.9 \%)$ had one or more live births, however, 29 (9.9\%) of participants though having been pregnant before, had never delivered a live birth (Table 1). 
Table 1: Sociodemographic characteristics of study participants

\begin{tabular}{|ll|}
\hline Participant characteristics & Total $(\mathrm{N}=\mathbf{2 9 2})$ (100\%) \\
\hline Age (Years) & \\
\hline$\leq 25$ & $177(60.6 \%)$ \\
\hline $26-35$ & $60(20.5 \%)$ \\
\hline$\geq 36$ & \\
\hline Gestation groups & $132(45.2 \%)$ \\
\hline$<35$ Weeks & $166(39.7 \%)$ \\
\hline $35-37$ Weeks & $44(15.1 \%)$ \\
\hline$>37$ weeks & \\
\hline Parity & $53(18.2 \%)$ \\
\hline Null para & $83(28.4 \%)$ \\
\hline One & $156(53.4 \%)$ \\
\hline Multiparous & \\
\hline
\end{tabular}

Maternal GBS colonization

Out of the 292 study participants $20.5 \%(n=60)$ tested positive to GBS recto-vaginal colonization on both culture and gram stain. GBS was cultured from vaginal swabs of $16.8 \%$ (49/292) participants while anorectal swabs of $18.8 \%$ (55/288) participants were GBS positive. On the other hand, $15.1 \%(44 / 292)$ of study participants had both rectal and vaginal GBS colonization.

Sociodemographic and obstetric characteristics of GBS rectovaginal colonization among pregnant women receiving antenatal care at Kenyatta National Hospital

The prevalence of GBS was highest among participants within the $26-35$ years age bracket at $13.0 \%(n=38)$, approximately one in twenty participants $(n=12,4.1 \%)$ aged above 36 years were GBS colonised. Participants within the 35-37 weeks gestation bracket had the highest prevalence of GBS ( $n=28 / 292,9.6 \%)$ followed by participants of gestational age below 35 weeks $(n=26 / 292,8.9 \%)$. The prevalence of GBS was lowest among participants of gestational age above 37 weeks $(n=8 / 292,2.1 \%)$.

The prevalence of GBS among participants with a history of stillbirth was $6.5 \%(n=19)$, abortion or ectopic pregnancy was $3.1 \%(n=9)$, preterm was $4.1 \%(n=12)$; for participants with a history of fore water break, more than 18 hours before labour, the prevalence was $3.4 \%(n=10)$. The prevalence was $2.1 \%(n=6)$ among participants allergic to penicillin, and $1.0 \%(n=3)$ among HIV-positive participants; participants with white coloured vaginal discharge had the highest GBS colonization with a prevalence of $11.0 \%(n=32)$ followed by clear coloured vaginal discharge with a prevalence of $4.5 \%$ $(n=13)$ (Table 2).

Table 2: Sociodemographic and obstetric characteristics of GBS colonized women 


\section{Sociodemographic and obstetric characteristics}

Negative $(N=232)$

n (\%)

Maternal age (Years)

$<26$

$26-35$

$>36$

Gestation age (weeks)

$<35$

$>37$

Parity

0

$(14.7 \%)$

69

(23.6\%)

120

(41.1\%)

88

$(30.1 \%)$

38

$(13.0 \%)$

1

$>1$
Positive $(\mathrm{N}=60)$

$\mathrm{P}$

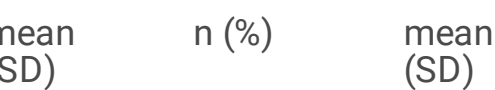

45

30.55

(5.53)

10

30.72

(3.4\%) (5.42)

139

$(47.6 \%)$

$38(13.0 \%)$

48

12

$(4.1 \%)$

$\begin{array}{llll}106 & 33.18 & 26 & 33.02 \\ (36.3 \%) & (5.31) & (8.9 \%) & (5.01)\end{array}$

28

(9.6\%)

$6(2.1 \%)$

Number of prior live births if parity $>0$

\begin{tabular}{|c|c|c|c|c|c|}
\hline 0 & $25(8.6 \%)$ & $\begin{array}{l}1.36 \\
(0.82)\end{array}$ & $4(1.4 \%)$ & $\begin{array}{l}1.54 \\
(1.05)\end{array}$ & \\
\hline$>0$ & $\begin{array}{l}164 \\
(56.2 \%)\end{array}$ & & $46(15.8 \%)$ & & \\
\hline Number of prior stillbirths & $\begin{array}{l}74 \\
(25.3 \%)\end{array}$ & $\begin{array}{l}0.63 \\
(0.96)\end{array}$ & $\begin{array}{l}19 \\
(6.5 \%)\end{array}$ & $\begin{array}{l}0.56 \\
(0.84)\end{array}$ & 0.935 \\
\hline $\begin{array}{l}\text { History of pregnancy loss in prior pregnancies (abortion } \\
\text { or ectopic) }\end{array}$ & $23(7.9 \%)$ & $\begin{array}{l}0.15 \\
(0.44)\end{array}$ & $9(3.1 \%)$ & $0.26(0.7)$ & 0.526 \\
\hline History of preterm birth in prior pregnancy & $\begin{array}{l}45 \\
(15.4 \%)\end{array}$ & $\begin{array}{l}0.37 \\
(0.82)\end{array}$ & $\begin{array}{l}12 \\
(4.1 \%)\end{array}$ & $\begin{array}{l}0.38 \\
(0.83)\end{array}$ & 0.945 \\
\hline
\end{tabular}

\section{Antimicrobial susceptibility pattern}

Penicillin G, ampicillin and vancomycin susceptibility pattern was tested on 58 samples while clindamycin susceptibility was tested on 46 samples. GBS bacterium isolated in this population had the highest resistance to penicillin $\mathrm{G}(72.4 \%, n=42 / 58)$ and ampicillin $(55.2 \%, n=32 / 58)$. Resistance to vancomycin and clindamycin was at $24.1 \%(n=14 / 58)$ and $30.4 \%(n=14 / 46)$ respectively. In general, GBS isolates from the anorectal canal were more resistant to tested antimicrobials in comparison to those isolated from the lower vagina. 


\begin{tabular}{|c|c|c|c|c|c|}
\hline \multirow{2}{*}{$\begin{array}{l}\text { Sociodemographic and obstetric characteristics } \\
\text { Rupture of membranes for > } 18 \text { hours before labour in } \\
\text { prior pregnancy }\end{array}$} & \multicolumn{5}{|c|}{ GBS culture results } \\
\hline & $\begin{array}{l}48 \\
(16.4 \%)\end{array}$ & $\begin{array}{l}0.58 \\
(0.79)\end{array}$ & $\begin{array}{l}10 \\
(3.4 \%)\end{array}$ & $0.5(0.77)$ & 0.688 \\
\hline Past history of neonatal death in first week of birth & $23(7.9 \%)$ & $\begin{array}{l}0.47 \\
(0.79)\end{array}$ & $9(3.1 \%)$ & $\begin{array}{l}0.48 \\
(0.77)\end{array}$ & 0.526 \\
\hline Past history of neonatal infection after birth & $25(8.6 \%)$ & $\begin{array}{l}0.48 \\
(0.79)\end{array}$ & $5(1.7 \%)$ & $\begin{array}{l}0.42 \\
(0.76)\end{array}$ & 0.782 \\
\hline $\begin{array}{l}\text { Fore water break in past pregnancy Rupture of } \\
\text { membranes? }\end{array}$ & $5(1.7 \%)$ & & $2(.7 \%)$ & & 0.636 \\
\hline Allergy to penicillin & & & & & 0.051 \\
\hline Yes & $9(3.1 \%)$ & $\begin{array}{l}0.47 \\
(0.83)\end{array}$ & $6(2.1 \%)$ & $\begin{array}{l}0.33 \\
(0.68)\end{array}$ & \\
\hline Don't Know & $\begin{array}{l}50 \\
(17.1 \%)\end{array}$ & & $7(2.4 \%)$ & & \\
\hline HIV status & & & & & 0.628 \\
\hline Positive & $12(4.1 \%)$ & $\begin{array}{l}0.05 \\
(0.22)\end{array}$ & $3(1.0 \%)$ & $\begin{array}{l}0.05 \\
(0.22)\end{array}$ & \\
\hline Colour of vaginal discharge & & & & & 0.942 \\
\hline Yellow & $25(8.6 \%)$ & $\begin{array}{l}2.83 \\
(0.85)\end{array}$ & $7(2.4 \%)$ & $2.85(0.9)$ & \\
\hline Brown & $\begin{array}{l}32 \\
(11.0 \%)\end{array}$ & & $8(2.7 \%)$ & & \\
\hline White & $\begin{array}{l}132 \\
(45.2 \%)\end{array}$ & & $32(11.0 \%)$ & & \\
\hline Clear & $\begin{array}{l}43 \\
(14.7 \%)\end{array}$ & & $\begin{array}{l}13 \\
(4.5 \%)\end{array}$ & & \\
\hline
\end{tabular}

Antimicrobial susceptibility pattern

Penicillin G, ampicillin and vancomycin susceptibility pattern was tested on 58 samples while clindamycin susceptibility was tested on 46 samples. GBS bacterium isolated in this population had the highest resistance to penicillin $\mathrm{G}(72.4 \%, \mathrm{n}=42 / 58)$ and ampicillin $(55.2 \%, n=32 / 58)$. Resistance to vancomycin and clindamycin was at $24.1 \%(n=14 / 58)$ and $30.4 \%(n=14 / 46)$ respectively. In general, GBS isolates from the anorectal canal were more resistant to tested antimicrobials in comparison to those isolated from the lower vagina.

Serotypes of isolated Group B Streptococcus bacteria and their antimicrobial pattern

Out of the 60 GBS positive samples, serotype testing was conducted on 53 samples; seven samples did not grow after repeated sub-culturing. All ten known GBS serotypes occurred in this population. Serotype la was the most common serotype isolated from $75.9 \%$ of cultures followed by serotype III at $62.0 \%$. Serotype IV was the least occurring serotype at $36.0 \%$.

There was high resistance to penicillin G and ampicillin by all isolated GBS serotypes that ranged from 68-84\% and 57$78 \%$ respectively. In comparison, resistance to vancomycin and clindamycin was low ranging between 16-26\% and 15$33 \%$ respectively.

Serotypes IV isolates were the most resistant to penicillin $\mathrm{G}$ and ampicillin at $83.3 \%$ and $77.8 \%$ respectively while serotype la had the highest resistance to clindamycin at 33.3\%; serotype VI was the most resistant to vancomycin at $25.9 \%$. 
Overall, serotype IV was the most resistant to all tested antimicrobials while serotype II was the least resistance to tested antimicrobials.

Association between GBS serotype and antimicrobial susceptibility among pregnant women receiving antenatal care at Kenyatta National Hospital.

As summarized in Table 3, being colonised with serotype la was associated with penicillin resistance (OR 4.8; Cl: 1.265$18.311, \mathrm{p}=0.021)$. Colonization with serotypes III (OR 6.84; Cl:1.899-24.672, p = 0.003), IV (OR 5.12; Cl:1.372-19.077, p= 0.015), VI (OR 4.45; Cl:1.353-14.653, $\mathrm{p}=0.014)$, and VIII (OR 4.67; Cl:1.255-17.358, p = 0.022) was associated with ampicillin resistance. None of the isolates was associated with either vancomycin or clindamycin resistance.

Table 3

Association between GBS serotype and antimicrobial pattern indicating OR

\begin{tabular}{|c|c|c|c|c|c|c|c|c|c|c|c|c|}
\hline \multirow[t]{2}{*}{ Serotype } & \multicolumn{3}{|c|}{ Penicillin G } & \multicolumn{3}{|c|}{ Ampicillin } & \multicolumn{2}{|c|}{ Vancomycin } & \multicolumn{3}{|c|}{ Clindamycin } & \multirow[b]{2}{*}{$\mathbf{P}$} \\
\hline & OR & $95 \% \mathrm{Cl}$ & $\mathbf{P}$ & OR & $95 \% \mathrm{Cl}$ & $P$ & OR & $95 \% \mathrm{Cl}$ & $\mathbf{P}$ & OR & $95 \% \mathrm{Cl}$ & \\
\hline la & 4.81 & $\begin{array}{l}1.265- \\
18.311\end{array}$ & 0.021 & 3.52 & $\begin{array}{l}0.926- \\
13.353\end{array}$ & 0.065 & 0.81 & $\begin{array}{l}0.180- \\
3.635\end{array}$ & 0.781 & 1.33 & $\begin{array}{l}0.294- \\
0.709\end{array}$ & 0.71 \\
\hline $\mathrm{lb}$ & 1.25 & $\begin{array}{l}0.343- \\
4.558\end{array}$ & 0.735 & 2.41 & $\begin{array}{l}0.684- \\
8.471\end{array}$ & 0.171 & 0.82 & $\begin{array}{l}0.198- \\
3.432\end{array}$ & 0.79 & 1.38 & $\begin{array}{l}0.312- \\
0.668\end{array}$ & 0.67 \\
\hline II & 1.08 & $\begin{array}{l}0.321- \\
3.626\end{array}$ & 0.902 & 2.73 & $\begin{array}{l}0.862- \\
8.625\end{array}$ & 0.088 & 0.54 & $\begin{array}{l}0.137- \\
2.157\end{array}$ & 0.385 & 0.33 & $\begin{array}{l}0.071- \\
0.154\end{array}$ & 0.15 \\
\hline III & 1.68 & $\begin{array}{l}0.490- \\
5.745\end{array}$ & 0.41 & 6.84 & $\begin{array}{l}1.899- \\
24.672\end{array}$ & 0.003 & 1.86 & $\begin{array}{l}0.426- \\
8.087\end{array}$ & 0.411 & 1.31 & $\begin{array}{l}0.307- \\
0.714\end{array}$ & 0.71 \\
\hline IV & 3 & $\begin{array}{l}0.717- \\
12.553\end{array}$ & 0.132 & 5.12 & $\begin{array}{l}1.372- \\
19.077\end{array}$ & 0.015 & 1.02 & $\begin{array}{l}0.254- \\
4.104\end{array}$ & 0.977 & 0.74 & $\begin{array}{l}0.158- \\
0.702\end{array}$ & 0.7 \\
\hline V & 1.17 & $\begin{array}{l}0.346- \\
3.933\end{array}$ & 0.804 & 1.33 & $\begin{array}{l}0.434- \\
4.094\end{array}$ & 0.615 & 1.5 & $\begin{array}{l}0.377- \\
5.965\end{array}$ & 0.565 & 0.76 & $\begin{array}{l}0.182- \\
0.714\end{array}$ & 0.71 \\
\hline VI & 3.38 & $\begin{array}{l}0.947- \\
12.098\end{array}$ & 0.061 & 4.45 & $\begin{array}{l}1.353- \\
14.653\end{array}$ & 0.014 & 1.66 & $\begin{array}{l}0.418- \\
6.606\end{array}$ & 0.47 & 1.5 & $\begin{array}{l}0.351- \\
0.585\end{array}$ & 0.59 \\
\hline VII & 1.89 & $\begin{array}{l}0.519- \\
6.868\end{array}$ & 0.334 & 3.48 & $\begin{array}{l}0.99- \\
12.242\end{array}$ & 0.052 & 0.83 & $\begin{array}{l}0.202- \\
3.435\end{array}$ & 0.801 & 0.29 & $\begin{array}{l}0.062- \\
0.124\end{array}$ & 0.12 \\
\hline VIII & 2.25 & $\begin{array}{l}0.567- \\
8.927\end{array}$ & 0.249 & 4.67 & $\begin{array}{l}1.255- \\
17.358\end{array}$ & 0.022 & 1.33 & $\begin{array}{l}0.286- \\
6.214\end{array}$ & 0.714 & 0.76 & $\begin{array}{l}0.149- \\
0.746\end{array}$ & 0.75 \\
\hline IX & 2.25 & $\begin{array}{l}0.478- \\
10.595\end{array}$ & 0.305 & 3 & $\begin{array}{l}0.676- \\
13.309\end{array}$ & 0.148 & 0.85 & $\begin{array}{l}0.141- \\
5.070\end{array}$ & 0.855 & 0.48 & $\begin{array}{l}0.087- \\
0.399\end{array}$ & 0.4 \\
\hline
\end{tabular}

Risk factors for Group B Streptococcus colonization among pregnant women receiving antenatal care at Kenyatta National Hospital.

Logistic regression was used to determine predictors of positive GBS colonization. The variables were analysed both individually and in combination to ascertain their ability to predict positive GBS colonization. None of the variables in this study was a predictor of positive GBS colonization as indicated by the greater than $0.05 \mathrm{p}$ value in table 4 .

Table 4: Risk factors of GBS among study participants 


\begin{tabular}{|llll|}
\hline GBS Results & Odds Ratio & 95\% Conf. Interval & P \\
\hline Maternal age (Years) & 1.0 & $0.9353-1.0581$ & 0.868 \\
\hline Parity & 1.1 & $0.7703-1.5138$ & 0.656 \\
\hline Parity group & 2.3 & $0.8746-5.9941$ & 0.092 \\
\hline Gestation Age & 1.0 & $0.9342-1.1051$ & 0.710 \\
\hline Gestation groups & 0.8 & $0.4456-1.5134$ & 0.528 \\
\hline Number of prior live births & 1.1 & $0.7692-1.5054$ & 0.669 \\
\hline Still births & 0.7 & $0.4587-1.1648$ & 0.187 \\
\hline History of pregnancy loss in prior pregnancies (abortion or ectopic) & 1.3 & $0.7671-2.1953$ & 0.331 \\
\hline History of preterm birth in prior pregnancy & 1.0 & $0.6433-1.5105$ & 0.948 \\
\hline Rupture of membranes for $>$ 18 hours before labour in prior pregnancy & 0.7 & $0.3037-1.6017$ & 0.396 \\
\hline Past history of neonatal death in first week of birth & 2.1 & $0.8019-5.6026$ & 0.130 \\
\hline Neonatal infection & 0.5 & $0.1493-1.6053$ & 0.238 \\
\hline Fore water break in past pregnancy/Rupture of membranes & 1.4 & $0.2276-8.4070$ & 0.725 \\
\hline
\end{tabular}

\section{Discussion}

At $20.5 \%$, the rectovaginal prevalence of GBS among pregnant women receiving antenatal care at KNH was slightly higher than that reported by prior studies in this region or similar settings. In a study conducted in Mombasa by Cools and Jespers (15), they reported a GBS prevalence of $20.2 \%$ while the prevalence has been reported to vary between 10 and $35 \%$ in the USA (4) and between 1 and $30 \%$ in other developing countries $(4,15-17)$. Even so, this prevalence is slightly lower than that reported by Salat et al, in a study conducted in the same population (9). Difference of the prevalence in the two studies could be explained by the difference in gestational ages of women who formed study participants of the two studies. Salat restricted his participants to women of gestational age 35 to 37 weeks while this study included participants from gestational ages 12 to 40 weeks. Previous studies (18) have reported gestational age of women as a risk factor to GBS with the prevalence being higher among women of gestational age 35 to 37 weeks $(5,18)$. This study agrees with this observation as grouping of participants based on gestational age, found those of gestational age 35 to 37 weeks to have higher prevalence $(9.6 \%)$ of GBS in comparison to other gestational age groups.

Similarly, the prevalence reported in the current study is higher than that reported by Lu, Li (19) in Beijing, China (7\%), Woldu, Teklehaimanot (20) in Ethiopia (7.2\%) and Seale and Koech (8) in Kilifi $(12 \%)(7,8,19)$. The variations in the prevalence reported in the current study, and that reported by Cools and Jespers (15) and Seale, Koech (8) agrees with findings by Stoll and Schuchat (16) of occurrence of regional variation in GBS prevalence even among people sharing geographical boundaries and with similar socio-economic conditions $(8,15,16)$. Similarly, the difference in the prevalence could be explained by the culture method used in identification of GBS. This study used Granada agar in isolating GBS which has higher ability to isolate GBS compared to blood agar plates used by Lu and Li (19). It has been noted that variation in GBS prevalence could be as a result of culture methods and type of medium used to isolate GBS (20).

The antimicrobial susceptibility pattern of isolated GBS showed high GBS resistance to penicillin G and ampicillin of $72.4 \%$ and $54.2 \%$ respectively. There was however low resistance to clindamycin and vancomycin at $30.4 \%$ and $24.1 \%$ respectively. Previous studies have reported GBS to be evenly susceptible to penicillin, ampicillin and cephalosporins (17, 
21) even though bacteria with increasing minimum inhibitory concentration to penicillin and ampicillin have been reported $(17,21)$. The high resistance of GBS to penicillin G reported in our study mirrors that reported by Mengist, Zewdie (22) of 77.3\% (22). Findings of the current study partly agrees with those of Lu, Li (19), Yoon, Jo (23) and Mengist, Zewdie (22) who reported a resistance to clindamycin of $55.7 \%, 55.4 \%$ and $50 \%$ respectively $(19,22,23)$. However, the resistance in the three studies is higher than that reported in the current study of $30.4 \%$. Nonetheless, the isolates in Yoon, Jo (23) and Lu, Li (19) studies retained 100\% susceptibility to penicillin, ampicillin and vancomycin. On the other hand, the resistance of GBS to clindamycin reported in our study is higher than that reported by Bolukaoto, Monyama (17) of $17.2 \%$, even so, Bolukaoto, Monyama (17) isolates retained $100 \%$ susceptibility to penicillin, ampicillin, vancomycin and high level gentamycin even though they had high resistance to tetracycline of $86.7 \%$ (17).

Increase in resistance of GBS to $\beta$-lactam antibiotics has been attributed to alterations in the penicillin binding protein $2 \times$ (21) while resistance to clindamycin has been attributed to presence of erm-methylase gene (24). In his study to determine antibiotic resistance of GBS among pregnant women in Garankuwa, South African, Bolukaoto, Monyama (17) reported methylation of ermB genes to be the single most common mechanism of resistance employed by isolated bacteria. Other mechanisms identified were efflux pump mediated by mefA genes and ermTR genes. This high resistance limits antibiotic use and restricts treatment to clindamycin and vancomycin.

All the known ten serotypes of GBS were found to be occurring among this study's population. The most occurring serotype was la (75.9\%) followed by III (62\%), V (56\%), VI (54\%), Ib (53.7\%), VII (53.5\%), IX (53.3\%), II (48\%) and VIII (44.2\%). Serotype IV was the least occurring at $36 \% .66 .7 \%$ of participants were found to harbour more than one serotype of GBS. These findings agree with Rench and Baker (25) who reported serotypes la, lb, II and III as the most occurring, similarly, they mirror Lu, Li (19) who isolated eight GBS serotypes among pregnant women in his study with the exception of VII and IX. Nine GBS serotypes (la, Ib, II-VIII) have been reported to occur in Europe and USA (26). Previous studies conducted in Kenya have reported the occurrence of six GBS serotypes la, III, V, VI, VII and VIII in a Mombasa cohort (15). Our findings agree with observations of Dutra, Alves (27) who reported variations in the regional distribution and occurrence of GBS serotypes as this study found serotype la to be the most occurring in this population while Cools et al reported serotype III as the most occurring among pregnant women in Mombasa $(15,27)$. It is however, important to note that serotype distribution in a population could change with time. Yoon, Jo (23) in a GBS study conducted over a 20 years period found the dominant serotypes to change with time (23).

Serotype la (80.5\%) and VI (81.5\%) had significant resistance to penicillin G while serotypes la (61\%), III (71\%), IV (77.8\%), VI (70.5), VII (65.25) and VIII (73.7\%) registered significant resistant to ampicillin. Colonization with these serotypes was also a predictor of antimicrobial resistance with being colonised with serotype la predicting for penicillin $\mathrm{G}$ resistance (OR 4.8; Cl: 1.265-18.311, $\mathrm{p}=0.021$ ) as was serotype VI (OR 3.38; Cl:0.947-12.098, $\mathrm{p}=0.061)$. Being colonized with serotypes III (OR 6.84; Cl:1.899-24.672, p = 0.003), IV (OR 5.12; Cl:1.372-19.077, p = 0.015), VI (OR 4.45; Cl:1.353-14.653, $\mathrm{p}=0.014)$, VII (OR 3.48; Cl:0.99-12.242, $\mathrm{p}=0.052)$ and VIII (OR 4.67; Cl:1.255-17.358, $\mathrm{p}=0.022)$ was a predictor for ampicillin resistance. Our findings differ from those by Yoon, Jo (23), who in their study, found no strains to be resistant to penicillin (23). They also reported a resistance of $93.8 \%$ to clindamycin by serotype $\mathrm{V}$. This level of resistance to clindamycin by serotype $\mathrm{V}$ is higher than that reported in our study of $22.7 \%$.

Though some of the participants in this study reported having a history of risk factors associated with GBS such as stillbirths, abortions, ectopic pregnancy, history of preterm births, history of neonatal deaths, history of neonatal infection and history of fore water break more than 18 hours to labour, no statistically significant association was found between these factors and GBS colonization in this study. Similarly, there was no association between maternal age, gestational age, parity and number of live birth with GBS colonization. Other studies have reported an association between GBS colonization and some of these risk factors. For examples Salat (9) had previously reported GBS colonization to be associated with a history of stillbirth in the same population as did Seale, Koech (8) in Kilifi and Doare, Jarju (5) in the 
Gambia who besides still birth, also noted GBS colonization to be associated with early onset neonatal disease and gestational age $(5,9)$. Even though the current study did not find any association between GBS colonization and associated risk factors, the role of GBS in causing stillbirths and neonatal sepsis cannot be ruled out given the relatively high GBS prevalence, stillbirths and neonatal sepsis in this setting.

\section{Conclusion}

The prevalence of group B streptococcus among pregnant women seeking antenatal services at $\mathrm{KNH}$ is high. Anorectal GBS colonization was higher in comparison to vaginal colonization. No significant association was found between GBS and stillbirths, abortions or ectopic pregnancy, history of preterm births, history of neonatal deaths, history of neonatal infection and history of fore water break more than 18 hours to labour. Group B streptococcus isolated in this study were resistant to all tested antimicrobials with the highest resistance being to penicillin $\mathrm{G}$ while the least resistance was to vancomycin. All known GBS serotypes were found occurring in this population with serotype la being the most prevalent. All serotypes had strains that were resistant to tested antimicrobials. There was a statistically significant association between isolation of serotypes la and VI and resistance to penicillin $\mathrm{G}$ while isolation of serotypes Ia, III, IV, VI, VII and VIII was associated with ampicillin resistance. None of the isolated serotypes was associated with either clindamycin or vancomycin resistance.

\section{Declarations}

Ethical approval and consent to participate: This study was approved by the Kenyatta National Hospital-University of Nairobi Ethics Research Committee (Study registration number P521/07/2016). The KNH-UoN ERC study approval number was $\mathrm{KNH}-\mathrm{ERC} / \mathrm{A} / 399$. Signed informed consent were obtained from all study participants before enrolling into the study.

\section{Consent for publication: Not applicable}

Availability of data and material: The dataset used in this study is available from the corresponding author upon reasonable request and upon approval from the Kenyatta National Hospital-University of Nairobi Ethics Research Committee.

Competing interests: All authors have no conflict of interest.

Funding: This study was funded by the National Research Fund of Kenya. The funders had no role in study design, data collection and analysis, decision to publish, or preparation of the manuscript

Authors contribution: CJS conceived, designed the study and was the primary author of this manuscript while ANM edited it. AO advice on the gynaecological procedures and data analysis plan while ANM advised on the microbiology analysis procedures. CJS coordinated the study and data analysis. The manuscript has been circulated to all co-authors and all co-authors have been given the opportunity to edit and provide feedback on this manuscript. 
Acknowledgments: Many thanks to Professor Raymond Scott McClelland who assisted in editing of the manuscript.

\section{References}

1. Mitima KT, Ntamako S, Birindwa AM, Mukanire N, Kivukuto JM, Tsongo K ea. Prevalence of colonization by Streptococcus agalactiae among pregnant women in Bukavu, Democratic Republic of the Congo. J Infect Dev Ctries. 2014;8(9):1195-2000.

2. Buchan BW, Olson WJ, Mackey TL, Ledeboer NA. Clinical evaluation of the walk-away specimen processor and ESwab for recovery of Streptococcus agalactiae isolates in prenatal screening specimens. J Clin Microbiol. 2014;52(6):2166-8.

3. El Aila NA, Tency I, Claeys G, Saerens B, Cools P, Verstraelen H, et al. Comparison of different sampling techniques and of different culture methods for detection of group B streptococcus carriage in pregnant women. BMC Infect Dis. 2010;10:285.

4. Gilbert R. Prenatal screening for group B streptococcal infection: gaps in the evidence. Int J Epidemiol. 2004;33(1):28.

5. Doare KL, Jarju S, Darboe S, Warburton F, Gorringe A, Heath PT, et al. Risk factors for Group B Streptococcus colonisation and disease in Gambian women and their infants. Journal of Infection. 2016;72:283-94.

6. Namavar Jahromi B, Poorarian S, Poorbarfehee S. The prevalence and adverse effects of group B streptococcal colonization during pregnancy. Arch Iran Med. 2008;11(6):654-7.

7. Woldu ZL, Teklehaimanot TG, Waji ST, Gebremariam MY. The prevalence of Group B Streptococus recto-vaginal colonization and antimicrobial susceptibility pattern in pregnant mothers at two hospitals of Addis Ababa, Ethiopia. Reprod Health. 2014;11:80.

8. Seale AC, Koech AC, Sheppard AE, Barsosio HC, Joyce Langat, mily Anyango, et al. Maternal colonisation with Streptococcus agalactiae, and associated stillbirth and neonatal disease in coastal Kenya. Nat Microbiol. 2016;1(7).

9. Salat M. Prevalence of GBS colonization in antenatal women at Kenyatta National Hospital [Masters Degree Thesis]. Nairobi: University of Nairobi; 2009.

10. MoH. KENYA REPRODUCTIVE, MATERNAL, NEWBORN, CHILD AND ADOLESCENT HEALTH (RMNCAH) INVESTMENT FRAMEWORK. In: Health Mo, editor. Nairobi: Government Press; 2016.

11. KNBS. Kenya Demographic and Health Survey 2014 In: Kenya National Bureau of Statistics, Ministry of Health, National AIDS Control Council, Kenya Medical Research Institute, National Council for Population and Development, The DHS Program II, editors. Nairobi: Government press; 2015.

12. UNDP. Sustainable Development Goals Knowledge Platform New York2016 [cited 201612 March]. Available from: https://sustainabledevelopment.un.org/sdgs.

13. KNH S. Health Records Annual Statistics. 2015.

14. Franklin R. Cockerill I, MD, Matthew A. Wikler M, MBA, FIDSA, Karen Bush P, Michael N. Dudley P, FIDSA, George M. Eliopoulos M, Dwight J. Hardy P, et al. Performance Standards for Antimicrobial Susceptibility Testing; Twenty-First Informational Supplement. In: Institute CaLS, editor. Pennsylvania: Clinical and Laboratory Standards Institute 2011. p. 100-4.

15. Cools P, Jespers V, Hardy L, Crucitti T, Delany-Moretlwe S, Mwaura M, et al. A Multi-Country Cross-Sectional Study of Vaginal Carriage of Group B Streptococci (GBS) and Escherichia coli in Resource-Poor Settings: Prevalences and Risk Factors. PLOS ONE. 2016. 
16. Stoll BJ, Schuchat A. Maternal carriage of group B streptococci in developing countries. Pediatr Infect Dis J. 1998;17(6):499-503.

17. Bolukaoto JY, Monyama CM, Chukwu MO, Lekala4 SM, Nchabeleng M, Maloba MRB, et al. Antibiotic resistance of Streptococcus agalactiae isolated from pregnant women in Garankuwa, South Africa. BMC Res Notes 2015;8(364).

18. Boyer KM, Gadzala CA, Burd LI, Fisher DE, Paton JB, Gotoff SP. Selective intrapartum chemoprophylaxis of neonatal group B streptococcal early-onset disease. I. Epidemiologic rationale. J Infect Dis. 1983;148(5):795-801.

19. Lu B, Li D, Cui Y, Sui W, Huang L, Lu X. Epidemiology of Group B streptococcus isolated from pregnant women in Beijing, China. Clinical Microbiology and Infection. 2014;20(6).

20. Woldu ZL, Teklehaimanot TG, Waji ST, Gebremariam MY. The prevalence of Group B Streptococus recto-vaginal colonization and antimicrobial susceptibility pattern in pregnant mothers at two hospitals of Addis Ababa, Ethiopia. Reproductive Health 2014;11:80.

21. Verani JR, McGee L, Schrag SJ. Prevention of Perinatal Group B Streptococcal Disease Revised Guidelines from CDC, 2010. Atlanta: Centers for Disease Control and Prevention (CDC), 2010 Contract No.: RR-10.

22. Mengist HM, Zewdie O, Belew A, Dabsu R. Prevalence and drug susceptibility pattern of group B Streptococci (GBS) among pregnant women attending antenatal care (ANC) in Nekemte Referral Hospital (NRH), Nekemte, Ethiopia. BMC Res Notes. 2017;10(388).

23. Yoon IA, Jo DS, Cho EY, Choi EH, Lee HJ, Lee H. Clinical significance of serotype $V$ among infants with invasive group B streptococcal infections in South Korea. International Journal of Infectious Diseases 2015;38:136-40.

24. Metcalf BJ, Chochua S, Jr REG, Hawkins PA, Ricaldi J, Li Z, et al. Short-read whole genome sequencing for determination of antimicrobial resistance mechanisms and capsular serotypes of current invasive Streptococcus agalactiae recovered in the USA. Clinical Microbiology and Infection 2017;23:574.e7e.e14.

25. Rench MA, Baker CJ. Neonatal sepsis caused by a new group B streptococcal serotype. J Pediatr. 1993;122(4):63840.

26. Ippolito D, James W, Tinnemore D, Huang R, Dehart M, Williams J. Group B streptococcus serotype prevalence in reproductive-age women at a tertiary care military medical center relative to global serotype distribution. BMC Infect Dis. 2010;10:336.

27. Dutra VG, Alves VM, Olendzki AN, Dias CA, de Bastos AF, Santos GO, et al. Streptococcus agalactiae in Brazil: serotype distribution, virulence determinants and antimicrobial susceptibility. BMC Infect Dis. 2014;14:323.

\section{Figures}




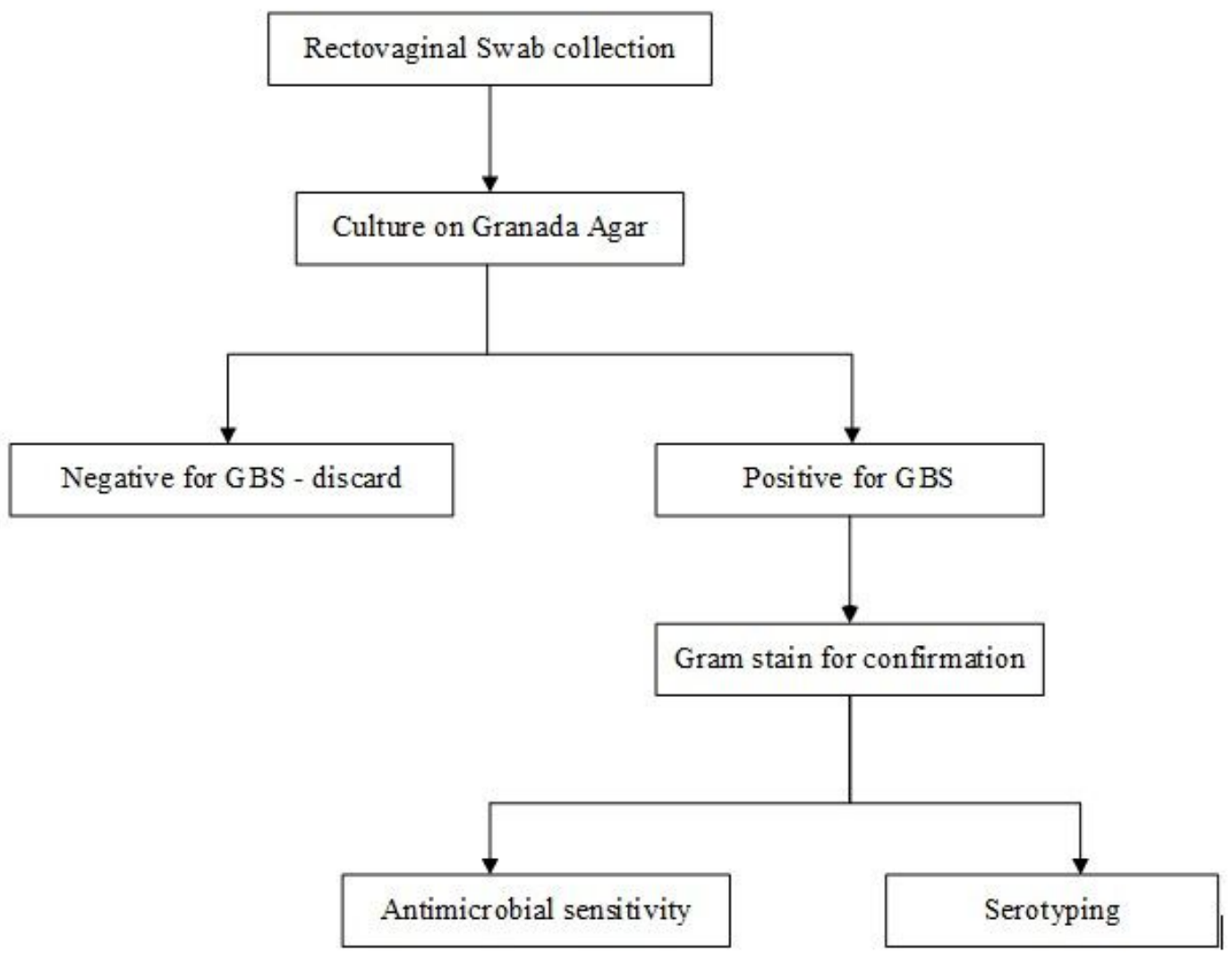

\section{Figure 1}

Flow chart showing steps followed in processing clinical specimens for GBS isolation 